\title{
Do White Shark Bites on Surfers Reflect Their Attack Strategies on Pinnipeds?
}

\author{
Erich Ritter $^{1,2}$ and Alexandra Quester ${ }^{3}$ \\ ${ }^{1}$ Department of Mathematics and Statistics, University of West Florida, Pensacola, FL 32514, USA \\ ${ }^{2}$ Global Shark Attack File, Shark Research Institute, Princeton, NJ 08540, USA \\ ${ }^{3}$ Department of Biology, University of Vienna, 1090 Vienna, Austria
}

Correspondence should be addressed to Erich Ritter; erichritter@att.net

Received 26 May 2016; Accepted 7 September 2016

Academic Editor: Yehuda Benayahu

Copyright (C) 2016 E. Ritter and A. Quester. This is an open access article distributed under the Creative Commons Attribution License, which permits unrestricted use, distribution, and reproduction in any medium, provided the original work is properly cited.

\begin{abstract}
The theory of mistaken identity states that sharks, especially white sharks, Carcharodon carcharias, mistake surfers for pinnipeds when looking at them from below and thus bite them erroneously. Photographs of surfer wounds and board damage were interpreted with special emphasis on shark size, wound severity, and extent of damage to a board. These were compared with the concurrent literature on attack strategies of white sharks on pinnipeds and their outcomes. The results show that the majority of damage to surfers and their boards is at best superficial-to-moderate in nature and does not reflect the level of damage needed to immobilize or stun a pinniped. It is further shown that the size distribution of sharks biting surfers differs from that in pinnipeds. The results presented show that the theory of mistaken identity, where white sharks erroneously mistake surfers for pinnipeds, does not hold true and should be rejected.
\end{abstract}

\section{Introduction}

As popular as shark bites are among the general public, there is a large amount of incorrect information associated with these incidents [1-3]. In the wake of shark bites, levels of erroneous information soar, and through continuous reinforcement in the mainstream media these errors may eventually become unchallenged facts [4-6].

The theory of mistaken identity has been proposed to explain why sharks likely bite surfers $[7,8]$. It states that a surfer resembles a pinniped when seen from below and therefore might accidentally get bitten. Although questioned in the past $[9,10]$, this theory has never been properly tested and, until proven correct, should merely be seen as an assumption and not be used in a factual manner [11-13]. To be valid, the theory of mistaken identity must support its basic theorem that a mistake by the sharks can indeed be established as the reason for biting a surfer.

The species mostly associated with the assumption of mistaken identity is the white shark, Carcharodon carcharias, which commonly feeds on pinnipeds such as otariids and phocids once it has grown large enough to hunt them down [14-16]. Smaller white sharks are likely not fast or agile enough to successfully hunt pinnipeds, and their tooth structure is also not yet suitable for gouging. Consequently, there is a minimal size or likely a size range, where white sharks start to become more effective in hunting pinnipeds [17]. Suppose that a white shark would mistake surfers for seals; the minimum size of sharks biting surfers should therefore be similar to the minimum size of those who successfully hunt and kill pinnipeds. Based on the above assumptions, two hypotheses were formulated and tested in this study: (1) the smallest size of white sharks biting surfers correlates with the minimum size of white sharks attacking pinnipeds, and (2) the general wound intensity on surfers and/or the damage caused to their boards matches the wound severity on pinnipeds.

\section{Methods}

We focused on incidents reported involving white sharks and surfers along the California and Oregon coasts of the Pacific US which occurred in the 50 years between 1966 and 
2015. All files were retrieved from the archives of the "Shark Research Committee" in Van Nuys, California, and the Shark Research Institute's "Global Shark Attack File" in Princeton, New Jersey. Sixty-seven incidents were logged between the chosen time period along California coast and Oregon coast which positively identified the involvement of a white shark and a surfer.

Through the years, there were a number of well publicized incidents involving white sharks along California and Oregon coasts. However, a few of these incidents could not be included in this project due to missing data.

\subsection{Reconstruction of Jaw Size and Body Length Based on}

Tooth Imprints. In white sharks, there is a direct relationship between interdental distance measurements, which reflects the gap between two adjacent teeth (from crown tip to crown tip), bite radii, describing a jaw's dimension along the front line of teeth, also known as the bite circumference, and a shark's length (e.g., [18-22]). Thus, in order to reconstruct the presumed length of a shark from file pictures, we measured either interdental distances or bite radii from upper or lower jaws, whatever were more suitable, and applied them to established log-log regressions by Lowry et al. (2009) [18] for the respective jaws (Table 1).

One problem we had when reconstructing the length of a shark from file pictures was that the great majority of images were not photographed with a ruler or in a plane position. Thus we could only reconstruct those sizes, where other objects of known size (e.g., surfboard models of known dimensions or human limbs) were available for comparison, and the view onto the wound or board damage was more or less normal and not distorted. Shark length reconstructions were rounded to 0.5 meters.

2.2. Wound and Board Damage Interpretation. Incidents involving sharks and surfers are commonly divided between victim wounds and board damage. Here, we did not differentiate between body or board damage since both are part of the actual silhouette when looked at from below; thus the intention of the shark remained the same regardless of the damage the shark caused.

The degree of wound severity changes with the motivation of a shark. When exploration is the underlying factor, a shark approaches an object rather slowly, applying a more gentle bite leading to mostly superficial damage (pers. obs.), whereas a predatory motivation involves a much more forceful bite to at least stun or immobilize the targeted prey. The same is reflected in damage to surfboards or surfers, where an exploratory bite results in rather superficial cuts and indentations, whereas a predatory bite would create more severe damage to the body and board.

Although some wound classifications for shark bites exist $[23,24]$, we used a modified combat injury coding scheme [25] for two major reasons (Table 2). First, the severity of a wound caused by a shark is generally determined by the degree of survivorship. However, even a superficial cut can have a fatal effect when, for example, the femoral artery is nicked. Despite the fact that such a wound would get the highest rating among general shark wound classifications
TABLE 1: Log-log regression between average interdental distance (IDD) or bite circumference (BC) and total body length of white sharks, Carcharodon carcharias, based on Lowry et al. (2009) [18]. Average interdental distance and bite circumference represent the dependent variables, whereas total length is the independent variable. $r^{2}=$ correlation coefficient; $p=$ significance level.

\begin{tabular}{lcccc}
\hline Type & Jaw & Regression & $r^{2}$ & $p$ \\
\hline IDD & Upper & $y=1.005 x-2.111$ & 0.98 & $<0.001$ \\
IDD & Lower & $y=0.925 x-1.808$ & 0.97 & $<0.001$ \\
\hline BC & Upper & $y=1.007 x-0.800$ & 0.98 & $<0.001$ \\
BC & lower & $y=0.966 x-0.743$ & 0.99 & $<0.001$ \\
\hline
\end{tabular}

$[23,24]$, it would not accurately reflect the intensity or force used by the shark. Second, as already mentioned, wound and board damage were treated equally; hence the intensity of board damage could only be expressed by degree of indentation, cut depth, and material loss. It should also be noted that a surfer's body is always partially protected by the board, depending on the position of the surfer during the incident; hence most injuries occur to arms, legs, and buttocks/back areas but not to the head and frontal side. It is the former areas that we focused our modified coding system on. Additionally, a shark is able to push a surfer from his board without leaving any mark or simply brush a surfer, which has been mentioned in some files; thus a severity index of " 0 " was added to the coding system.

The wound descriptions in the evaluated files stemmed from the reports by medical personnel, first responders, and case investigators and were transformed into the coding system by us. Likewise, board damage was also weighted and coded by us.

2.3. Length of White Sharks When Attacking Pinnipeds. The size of a white shark when it starts to consider a pinniped as potential prey or starts to get some hunting experience was assumed to be in the length range of $3.5 \mathrm{~m}$ to $4.5 \mathrm{~m}[7,19,26]$. This assumption is very conservative and white sharks even below $3 \mathrm{~m}$ have been known to successfully attack pinnipeds [26]. However, these attacks mainly involved small sized pinnipeds and are rather the exception along the California coast, for example, [26]. Two more size groups were added in addition to the range above: below $3.5 \mathrm{~m}$ for animals that would not yet consider pinnipeds as a food source due to their insufficiently developed teeth structure [7] or skill set and above $4.5 \mathrm{~m}$ for sharks that include pinnipeds in their regular diet.

2.4. Wound Severity of Pinnipeds. On very rare occasions, fatally injured pinnipeds wash up on shores [27] offering a limited glimpse of a white shark's first strike. Pictures of wounded or killed pinnipeds were gathered from the internet and compared with concurrent literature [28-31]. Although the bodily target zones vary between otariids and phocids and initial strikes deviate [30], the pictures' main purpose was to obtain a general idea of minimal wound severity and how those bites compared to bites on surfers. It is understood that wound appearances on pinnipeds can be distorted due to attack angle, overlapping bites, and decomposition, as well as 
TABLE 2: Categorization of body areas, wound intensity, and board damage caused by white sharks during incidents with surfers.

\begin{tabular}{|c|c|c|c|c|}
\hline Type & $\begin{array}{l}\text { Severity } \\
\text { index }\end{array}$ & Back/buttocks & Arm/leg & Board \\
\hline None & 0 & \multicolumn{2}{|c|}{ Some bruising } & No visual damage \\
\hline Minor & 1 & \multicolumn{2}{|c|}{ Superficial cuts, lacerations, and punctures } & $\begin{array}{c}\text { Scratches and very } \\
\text { superficial } \\
\text { indentations }\end{array}$ \\
\hline Moderate & 2 & \multicolumn{2}{|c|}{ Subcutaneous damage to muscle, without tissue loss } & $\begin{array}{l}\text { Moderate cuts and } \\
\text { indentations with a } \\
\text { maximal mid teeth } \\
\text { penetration, with } \\
\text { no loss of material }\end{array}$ \\
\hline Serious & 3 & Deep cuts, tissue loss, & and bone damage & $\begin{array}{c}\text { Deep cuts and } \\
\text { indentations with a } \\
\text { full teeth } \\
\text { penetration, with } \\
\text { small board parts } \\
\text { missing }\end{array}$ \\
\hline Severe & 4 & Organ damage with and without tissue loss & Large tissue loss, including partial limb loss & $\begin{array}{l}\text { Partial bite pieces } \\
\text { missing, heavy } \\
\text { damage }\end{array}$ \\
\hline Total & 5 & Extended organ damage, with heavy tissue loss & Entire limb loss & $\begin{array}{c}\text { Full bite piece(s) } \\
\text { missing, total } \\
\text { damage }\end{array}$ \\
\hline
\end{tabular}

other factors $[28,29]$. In addition, it is unknown how initial strikes looked of those pinnipeds that were killed and eaten. Therefore data from accessible pictures of pinnipeds that were either injured or fatally wounded may only be used to better understand approach direction of a shark but is limited to understand necessary bite intensity needed to incapacitate the prey.

2.5. Miscellaneous Collected Data. It was recorded whether a person and/or a board was bitten once, twice, or even a third time. In addition, we also tallied water depth, visibility, and the general weather situation (overcast, clear, rainy, etc.) at the incident site. Water depth and visibility were rather vague terms, since they were based on the sole account of the victim. However, both these factors together with the brightness of the sky offered a general idea about environmental circumstances at the time of the incident.

\section{Results}

Sixty-seven incidents were logged between 1966 and 2015 along California and Oregon coasts which positively identified the involvement of a white shark biting a surfer.

3.1. Reconstructed Shark Sizes. Twenty-four cases offered enough clear imprints to reliably reconstruct the length of the shark through the log-log regressions developed by Lowry et al. (2009) [18]. Fifty percent of these incidents were caused by juvenile white sharks with a length between $2.5 \mathrm{~m}$ and $3.5 \mathrm{~m}$, followed by another $25 \%$ between $3.5 \mathrm{~m}$ and $4.5 \mathrm{~m}$. No white shark with a length of less than $2.5 \mathrm{~m}$ was involved in any incident.

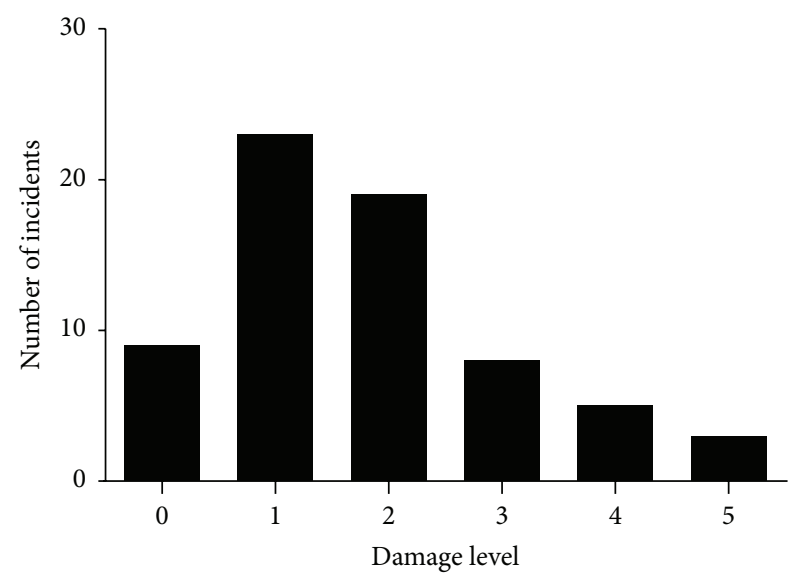

Figure 1: Level of damage compared to number of incidents. $0=$ no damage to body and board; $1=$ minor; 2 = moderate; $3=$ serious; 4 $=$ severe; $5=$ total.

3.2. Level of Damage to Person and Board. The number of sharks associated with various levels of damage is shown in Figure 1. Approximately, $13 \%$ of all incidents $(N=67)$ showed no wounds or board damage but were simple bumps or collisions with or without forcing the surfer off the board. Of the incidents that caused damage to the surfer or the board, more than $72 \%$ reflected either minor or moderate damage. Using the six-point scale, the average wound damage was 1.8 ( $\mathrm{SE}=0.2 ; N=67)$, with " 0 " and " 5 " indicating no damage to body and board and maximum damage to body and board, respectively (Table 2). 
A shark either bit a second time or readjusted its initial bite in approximately $21 \%$ of the reported incidents. Even when a shark grabbed the surfer or board for a second time, the damage in more than $64 \%$ of the multiple bite cases remained either minor or nonexistent. A third bite was never reported.

3.3. Environmental Factors. The weather was described in 47 incidents $(70.1 \%$ of all cases). The sky was either overcast or clear in close to $90 \%$ of these incidents.

The average water depth at the sites where incidents occurred was approximately $4 \mathrm{~m}(\mathrm{SE}=0.3 ; N=28)$ with visibility down to the bottom in $10.7 \%$ of these cases.

\section{Discussion}

When the first white sharks evolved more than 15 million years ago, most pinniped species had already existed [32]. Many of the now-extinct shark species belonging to the white shark lineage roamed the shores much earlier than the recent white shark species $[33,34]$ and pinnipeds were already part of their diet [35]. Such a long period of parallel evolution must have enabled even early sharks of that lineage to recognize the shape and form of a pinniped from every angle and not only the silhouette from directly below. This is further supported by the concept that sharks possess a search image for pinnipeds [36]. As the term implies, a shark carries an image in its mind, which is compared to any image encountered until matched. Seeing an object from below towards the bright(er) surface would be the easiest way to achieve this, but the search image is applicable from other angles as well.

White sharks undergo dietary changes while growing which include a broad spectrum of prey species of varying shapes, sizes, and speeds $[16,37]$. Thus, different strategies are continuously required to successfully hunt down these various prey species. In order to be successful, an identification process is necessary to distinguish newly encountered targets. If such an item is identified, an appropriate action pattern may take place. If no verification of an examined object transpires, the shark may further explore the item or turn away. The vision of white sharks is very acute [38] and even the smallest objects on the surface are detectable from relatively large depths [39]. Following the general decision-making process involved in catching prey [40], the decision to continue or abort a potential attack, under the assumption that a surfer does not resemble a pinniped, must lie within the detection and identification phase but occur before the actual approach starts. Thus, biting a surfer may represent a conscious attempt to further investigate the unfamiliar object rather than going after a surfer because the shark has been misled.

4.1. Comparison of Wound Severity Differences between Pinnipeds and Surfers. Analysis of the data revealed that the hypothesis that the general wound pictures on pinnipeds match the wounds on surfers and damage to their boards can be rejected.

White sharks show highly evolved attack strategies for pinnipeds [19], but, with the exception of some observations of breaching as the final step of such a strategy [26], most interpretations stem from observations of bite wounds and scarring of pinnipeds and other marine mammals [28, 29]. The most prominent factor underlying breaching is the speed of the shark, and its most notable effect would be to stun the pinniped when hitting it [17].

Although wounds on pinnipeds caused by white sharks have been studied in the past [30], most of the knowledge is based on washed up dead specimens or the observation of wounds on those that got away [31, 41], leaving a question mark about the nature of initial strikes and killing bites of pinnipeds that were eaten. Pinnipeds are highly agile animals that are able to outmaneuver a white shark when they are aware of the predator's presence (pers. obs.); thus the shark's initial strike needs to be fast and forceful to prevent the pinniped from escaping. If the theory of mistaken identity would be correct, most surfers should then also show severe wounds, reflecting those seen in pinnipeds. This is not the case. In more than $76 \%$ of all events, the shark caused damage to a person or a board that would not have incapacitated a pinniped. These mostly superficial or moderate levels of damage suggest a curious animal rather than a hunting one. This is strongly supported by the $15 \%$ of incidents where neither the person nor the board was affected. It would be pointless for a white shark to successfully hunt down a pinniped but then just bump into it and let go.

In more than $64 \%$ of incidents, where a shark bit the surfer and its board a second time, the level of damage remained between no damage and minor damage. If the shark were mistaken in the first place and even after the first bite still under the impression of having attacked a pinniped, the question arises of what the purpose of a second superficial bite would be. A satisfactory answer cannot be given from that viewpoint. However, applying two bites back to back from an exploratory angle suggests an increase in contact time or a necessary change in bite angle to optimize contact for sensory oriented purposes.

4.2. Size Range of White Sharks and Exposure to Pinnipeds. Younger white sharks below $3.5 \mathrm{~m}$ in length do not generally feed on pinnipeds, since their mobility and speed are not yet sufficient for this very agile prey; and their tooth structure is also not yet adequately developed for gouging [7]. Also, the minimum size of white sharks that hunt pinnipeds may vary among locations [16]. For this study, we used a conservative approach and assumed that sharks below $3.5 \mathrm{~m}$ were not yet involved in hunting pinnipeds and set a range between $3.5 \mathrm{~m}$ and $4.5 \mathrm{~m}$ body length for sharks where they start to do so. It can be assumed that, during this transition, some of them may use surface bound objects, inanimate and animate, including surfers, for practice runs, that is, target practice or object play.

The existence of play behavior has been established in white sharks [42] and could explain why they occasionally approach surfers in a fast and overpowering manner despite the unknown nature of the object [43]. Object play is an important behavior in many animal groups to hone skills of various kinds [44-46]; thus, practicing potential approach patterns for hunting prey would be a feasible explanation for some of these incidents involving sharks and surfers. This 
behavior could clarify why eight of the 67 incidents revealed rather extensive wounds, with damage level of 4 and 5. The investigation of McCosker and Lea (2006), who targeted the same eight incidents [47], confirmed the severity levels we chose. Of these eight sharks, seven were rather large, with a size of at least $4 \mathrm{~m}$ and up to about $6 \mathrm{~m}$. However, besides the fact that object play among such large animals, or target practice for that matter, could easily lead to these massive wounds, it should be kept in mind that secondary wounds [43], caused by the victim's reactions, can be as severe as or even worse than the bite itself.

Object play is especially crucial in a young predator's life to get as much information about its own environment and its inhabitants as possible. To obtain as much information as possible, different strategies are needed, and so even biting an unfamiliar object in a restrained, strike-like manner might be employed [48]. This idea would explain why a third of all involved sharks in this study were smaller than $3.5 \mathrm{~m}$. The observation that more smaller sharks are involved in incidents with surfers rather than with pinnipeds suggests that the first hypothesis that sharks of similar, minimal size hunt surfers and pinnipeds can also be rejected. This conclusion is also supported by Clua and Reid (2013) [49] who evaluated an incident from New Caledonia, where a white shark less than $3 \mathrm{~m}$ long killed a surfer.

4.3. Approaching Unfamiliar Objects. The way white sharks move to investigate and bite inanimate objects has been described for a wide variety of items (e.g., [9, 36, 39, 50-52]). These observations range from indiscriminate approaches regarding shape, size, or color of the offered objects to oriented approaches on prey-like decoys. The common denominator in these studies is that the response of white sharks to inanimate objects revolves around their visual acuity. This raises the question of how surfers are categorized by sharks, since they fit both categories, inanimate and animate. Based on the idea of mistaken identity, the shark would be guided through its vision and the assumption that the object is animate. However, the silhouette is largely caused by the board, an inanimate shape. Accepting that sharks can differentiate between these two states, there is no evidence that they would not be capable of doing so with surfers.

4.4. Water Depth and Visibility. The working basis of the mistaken identity theory is the silhouette similarity between a pinniped and surfer when looked at from directly below. However, the average depth among the examined cases was around $4 \mathrm{~m}$, forcing a shark to move in a rather shallow angle, which changes the silhouette into something completely different than what would be seen from right below. In addition, the visibility under water hardly exceeded a few meters for any of the examined cases, making visual contact a very close proximity affair $[53,54]$. Needing to get close before visual contact can be established, as well as facing something unfamiliar since a search image cannot be confirmed, will most likely lead to a rather cautious contact which is reflected by the majority of superficial-to-moderate bites, including mere bumps.

\section{Competing Interests}

The authors declare that they have no competing interests.

\section{Acknowledgments}

The authors thank Ralph Collier and Marie Levine for their assistance with the incident files for this project.

\section{References}

[1] E. Ritter, K. Lutz, and M. Levine, "When humans and sharks meet," in New Developments in the Psychology of Motivation, F. Olsson, Ed., pp. 45-53, Nova Biomedical Books, New York, NY, USA, 2008

[2] B. Hobdell, How to Avoid Shark Attacks: What the Tourist Companies Don't Want You to Know, Amazon Digital Services, Seattle, Wash, USA, 2011.

[3] D. J. Kloeckener, Jaws of Life: How to Avoid Shark Attacks, Amazon Digital Services, 2015.

[4] T. B. Allen, Shark Attack: Their Causes and Avoidance, Lyon Press, 2001.

[5] R. Reid, Shark!: Killer Tales from the Dangerous Depths, Allen and Unwin, 2011.

[6] A. MacCormick and R. Green, The Mammoth Book of Shark Attacks, Running Press, 2013.

[7] T. C. Tricas and J. E. McCosker, "Predatory behavior of the white shark (Carcharodon carcharias), with notes on its biology," Proceedings of the California Academy of Science, vol. 43, pp. 221238, 1984.

[8] R. Lea and J. McCosker, "Shark-human interaction in the eastern North Pacific: an update and analysis," 1993, http:// archive.rubicon-foundation.org/xmlui/handle/123456789/6329.

[9] R. S. Collier, M. A. Marks, and R. W. Warner, "White shark attacks on inanimate objects along the Pacific coast of North America," in Great White Shark: The Biology of Carcharodon carcharias, A. Klimley and D. G. Ainley, Eds., pp. 217-222, Academic Press, San Diego, Calif, USA, 1996.

[10] E. Ritter, "Sharks-Mistaken identity?" in Encyclopedia of Animal Behavior, M. Bekoff, Ed., pp. 963-964, Greenwood Press, Westport, Conn, USA, 2004.

[11] S. J. Lamberth, "White shark and other chondrichthyan interactions with the beach-seine (treknet) fishery in False Bay, South Africa," African Journal of Marine Science, vol. 28, no. 3-4, pp. 723-727, 2006

[12] E. Clua, P.-M. Bescond, and D. Reid, "Fatal attack by a juvenile tiger shark, Galeocerdo cuvier, on a kitesurfer in New Caledonia (South Pacific)," Journal of Forensic and Legal Medicine, vol. 25, pp. 67-70, 2014.

[13] C. Neff, "Human perceptions and attitudes towards sharks," in Sharks: Conservation, Governance and Management, E. J. Techera and N. Klein, Eds., pp. 107-132, Routledge, London, UK, 2014.

[14] A. P. Klimley, "The areal distribution and autoecology of the white shark, Carcharodon carcharias, off the west coast of North America," Memoirs of Southern California Academy of Science, vol. 9, pp. 15-40, 1985.

[15] J. G. Casey and H. L. Pratt, "Distribution of the white shark, Carcharodon carcharias, in the western North Atlantic," Memoirs of Southern California Academy of Science, vol. 9, pp. 2-14, 1985. 
[16] N. Hussey, H. McCann, G. Cliff et al., "Size-based analysis of diet and trophic position of the white shark, Carcharodon carcharias, in South African waters," in Global Perspective on the Biology and the Life History of the White Shark, M. Domeier, Ed., pp. 27-49, CRC Press, Boca Raton, Fla, USA, 2012.

[17] R. A. Martin, D. K. Rossmo, and N. Hammerschlag, "Hunting patterns and geographic profiling of white shark predation," Journal of Zoology, vol. 279, no. 2, pp. 111-118, 2009.

[18] D. Lowry, A. L. F. de Castro, K. Mara et al., "Determining shark size from forensic analysis of bite damage," Marine Biology, vol. 156, no. 12, pp. 2483-2492, 2009.

[19] R. A. Martin, N. Hammerschlag, R. S. Collier, and C. Fallows, "Predatory behaviour of white sharks (Carcharodon carcharias) at Seal Island, South Africa," Journal of the Marine Biological Association of the United Kingdom, vol. 85, no. 5, pp. 1121-1135, 2005.

[20] K. Shimada, "The relationship between tooth size and total body length in the white shark, Carcharodon carcharias (Lamniformes: Lamnidae)," Journal of Fossil Research, vol. 35, pp. 2833, 2002.

[21] E. K. Ritter and M. Levine, "Bite motivation of sharks reflected by the wound structure on humans," The American Journal of Forensic Medicine and Pathology, vol. 26, no. 2, pp. 136-140, 2005.

[22] J. E. Randall, "Size of the great white shark (Carcharodon)," Science, vol. 181, no. 4095, pp. 169-170, 1973.

[23] D. H. Davies and G. D. Campbell, "The aetiology, clinical pathology and treatment of shark attack," Journal of the Royal Naval Medical Service, vol. 48, pp. 110-136, 1962.

[24] A. K. Lentz, G. H. Burgess, K. Perrin, J. A. Brown, D. W. Mozingo, and L. Lottenberg, "Mortality and management of 96 shark attacks and development of a shark bite severity scoring system," The American Surgeon, vol. 76, no. 1, pp. 101-106, 2010.

[25] M. M. Lawnick, H. R. Champion, T. Gennarelli et al., "Combat injury coding: a review and reconfiguration," Journal of Trauma and Acute Care Surgery, vol. 75, no. 4, pp. 573-581, 2013.

[26] C. Fallows, R. A. Martin, and N. Hammerschlag, "Comparisons between white shark-pinniped interactions at Seal Island (South Africa) with other sites in California," in Global Perspective on the Biology and the Life History of the White Shark, M. Domeier, Ed., pp. 105-117, CRC Press, Boca Raton, Fla, USA, 2012.

[27] B. J. LeBoeuf, "Hunting and migratory movements of white sharks in the eastern North Pacific," Memoirs of National Institute of Polar Research Special Issue, vol. 58, pp. 89-100, 2004.

[28] D. G. Ainley, R. P. Henderson, H. R. Huber et al., "Dynamics of white shark/pinniped interactions in the Gulf of the Farallones," Memoirs of Southern California Academy of Science, vol. 9, pp. 109-122, 1985.

[29] J. E. McCosker, "White shark attack behavior: observations of and speculations about predator and prey strategies," Memoirs of Southern California Academy of Science, vol. 9, pp. 123-135, 1985.

[30] A. Klimley, P. Pyle, and S. Anderson, "The behavior of white sharks and their pinniped prey during predatory attacks," in Great White Shark: The Biology of Carcharodon carcharias, A. Klimley and D. G. Ainley, Eds., pp. 175-191, Academic Press, San Diego, Calif, USA, 1996.

[31] B. J. LeBoeuf, R. M. Riedman, and R. S. Keyes, "White shark predation on pinnipeds in California coastal waters," Fishery Bulletin, vol. 80, no. 4, pp. 891-895, 1982.
[32] S. P. Applegate and L. Espinosa-Arrubarrena, "The fossil history of Carcharodon and its possible ancestor, Cretolamna: a study in tooth Identification," in Great White Shark: The Biology of Carcharodon carcharias, A. Klimley and D. G. Ainley, Eds., pp. 19-36, Academic Press, San Diego, Calif, USA, 1996.

[33] M. D. Uhen, "Evolution of marine mammals: back to the sea after 300 million years," The Anatomical Record, vol. 290, no. 6, pp. 514-522, 2007.

[34] G. Casey and H. Cappetta, "The Eocene selachian fauna from the Fayum depression in Egypt," Palaeontographica Abteilung A, vol. 212, pp. 1-30, 1990.

[35] R. W. Purdy, "Paleoecology of fossil white sharks," in Great White Shark: The Biology of Carcharodon carcharias, A. Klimley and D. G. Ainley, Eds., pp. 67-78, Academic Press, San Diego, Calif, USA, 1996.

[36] S. Anderson, R. Henderson, P. Pyle, and D. Ainley, "White shark reactions to unbaited decoys," in Great White Shark: The Biology of Carcharodon carcharias, A. Klimley and D. G. Ainley, Eds., pp. 223-228, Academic Press, San Diego, Calif, USA, 1996.

[37] J. A. Estrada, A. N. Rice, L. J. Natanson, and G. B. Skomal, "Use of isotopic analysis of vertebrae in reconstructing ontogenetic feeding ecology in white sharks," Ecology, vol. 87, no. 4, pp. 829834, 2006.

[38] S. H. Gruber and J. L. Cohen, "Visual system of the white shark, Carcharodon carcharias, with emphasis on retinal structure," Memoirs of Southern California Academy of Science, vol. 9, pp. 67-72, 1985.

[39] W. R. Strong, "Shape discrimination and visual predatory tactics in white sharks," in Great White Shark: The Biology of Carcharodon carcharias, A. Klimley and D. G. Ainley, Eds., pp. 229240, Academic Press, San Diego, Calif, USA, 1996.

[40] J. A. Endler, "Defense against predators," in Predator-Prey Relationships: Perspectives and Approaches from the Study of Lower Vertebrates, M. E. Feder and G. V. Lauder, Eds., pp. 109134, University of Chicago Press, Chicago, Ill, USA, 1986.

[41] B. J. LeBoeuf and D. E. Crocker, "Diving behavior of elephant seals: implications for predator avoidance," in Great White Shark: The Biology of Carcharodon carcharias, A. Klimley and D. G. Ainley, Eds., pp. 193-206, Academic Press, San Diego, Calif, USA, 1996.

[42] G. Burghardt, The Genesis of Animal Play: Testing the Limits, MIT Press, Cambridge, Mass, USA, 2006.

[43] E. Ritter and M. Levine, "Use of forensic analysis to better understand shark attack behaviour," Journal of Forensic OdontoStomatology, vol. 22, no. 2, pp. 40-46, 2004.

[44] S. M. McDonnell and A. Poulin, "Equid play ethogram," Applied Animal Behaviour Science, vol. 78, no. 2-4, pp. 263-290, 2002.

[45] M. Bekoff and J. A. Byers, Animal Play: Evolutionary, Comparative, and Ecological Perspectives, Cambridge University Press, Cambridge, UK, 1998.

[46] P. Martin and T. Caro, "On the function of play and its role in behavioral development," in Advances in the Study of Behavior, J. Rosenblatt, C. Beer, M. Bushnell, and P. Slater, Eds., vol. 15, pp. 59-103, Academy Process, New York, NY, USA, 1985.

[47] J. E. McCosker and R. N. Lea, "White shark attacks upon humans in California and Oregon, 1993-2003," Proceedings of the California Academy of Sciences, vol. 57, no. 17, pp. 479-501, 2006.

[48] M. Heithaus, "Predator-prey interactions," in Biology of Sharks and Their Relatives, J. Carrier, J. Musick, and M. Heithaus, Eds., pp. 488-512, CRC Press, Boca Raton, Fla, USA, 2012. 
[49] E. Clua and D. Reid, "Features and motivation of a fatal attack by a juvenile white shark, Carcharodon carcharias, on a young male surfer in New Caledonia (South Pacific)," Journal of Forensic and Legal Medicine, vol. 20, no. 5, pp. 551-554, 2013.

[50] D. Miller and R. Collier, "Shark attacks in California and Oregon, 1926-1979," California Fish and Game, vol. 67, pp. 76104, 1980.

[51] R. Lea and D. Miller, "Shark attacks off the California and Oregon coasts: an update, 1980-1984," Memoirs of Southern California Academy of Science, vol. 9, pp. 136-150, 1980.

[52] N. Hammerschlag, R. Martin, C. Fallows et al., "Investigatory behavior toward surface objects and non consumptive strikes on seabirds by white sharks, Carcharodon carcharias, at Seal Island, South Africa (1997-2010)," in Global Perspective on the Biology and the Life History of the White Shark, M. Domeier, Ed., pp. 91-103, CRC Press, Boca Raton, Fla, USA, 2012.

[53] M. Doron, M. Babin, A. Mangin, and O. Hembise, "Estimation of light penetration, and horizontal and vertical visibility in oceanic and coastal waters from surface reflectance," Journal of Geophysical Research: Oceans, vol. 112, no. 6, 2007.

[54] G. Horváth and D. Varjú, "Underwater refraction-polarization patterns of skylight perceived by aquatic animals through Snell's window of the flat water surface," Vision Research, vol. 35, no. 12, pp. 1651-1666, 1995. 

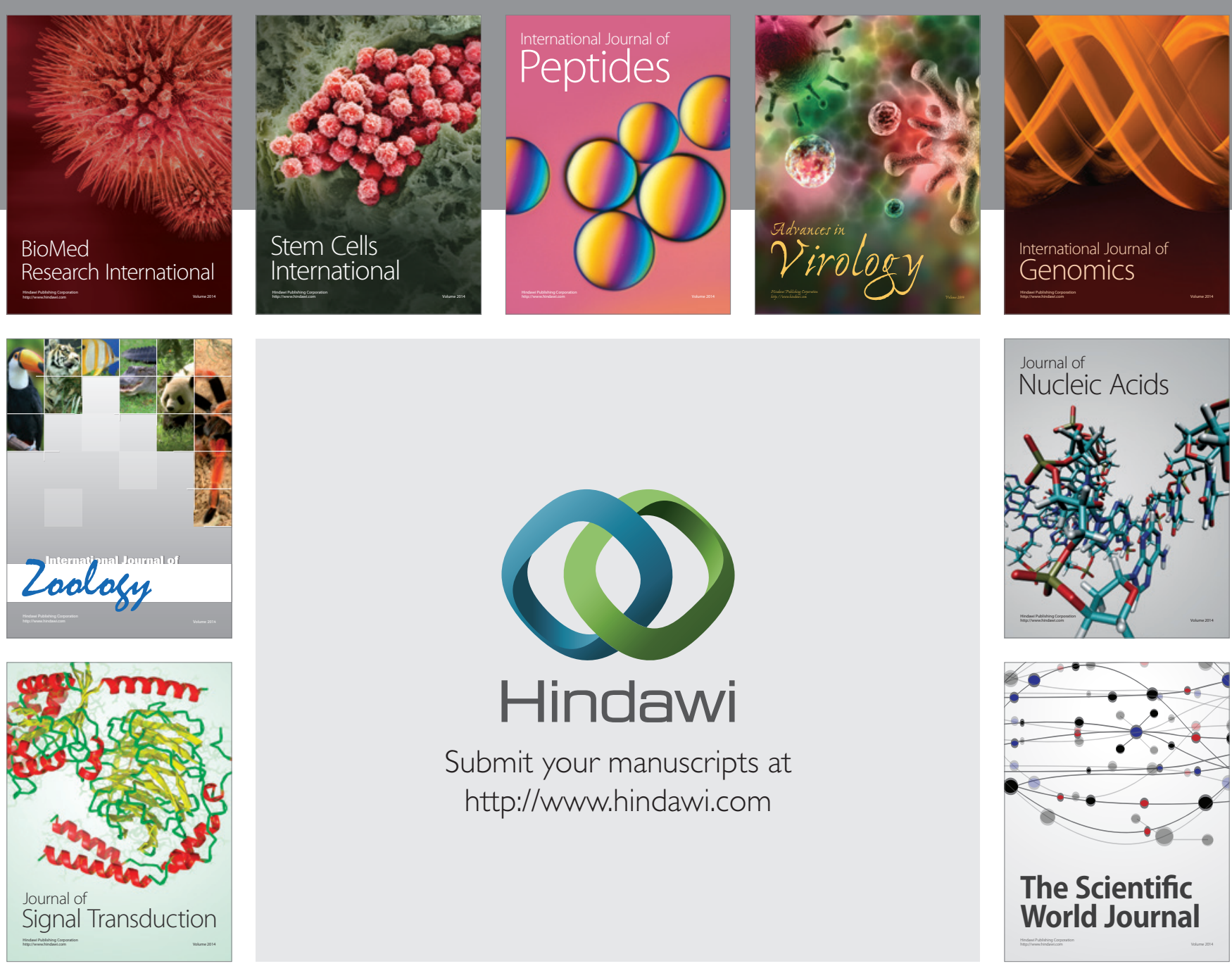

Submit your manuscripts at

http://www.hindawi.com
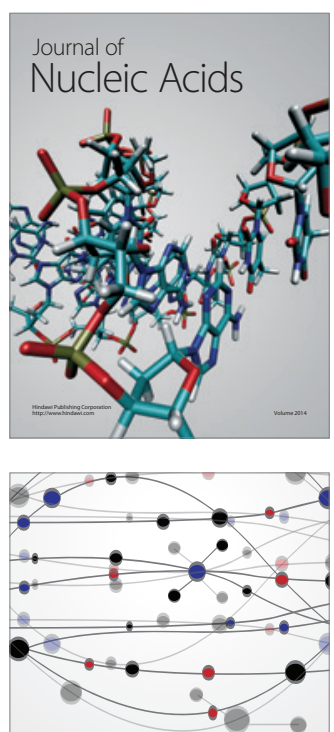

The Scientific World Journal
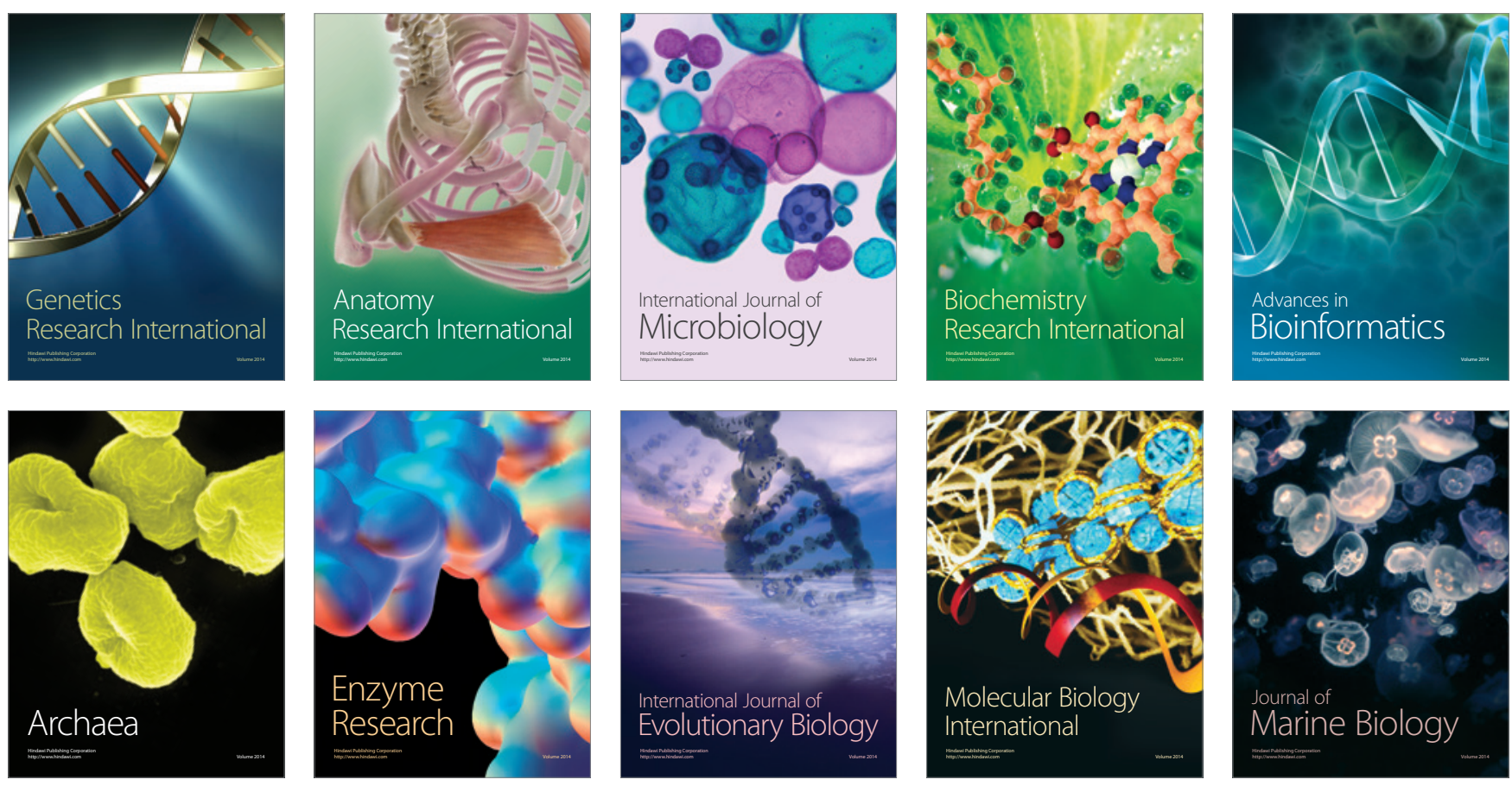